\title{
Altered mitochondrial epigenetics associated with subchronic doxorubicin cardiotoxicity
}

\author{
André Ferreira $^{\mathrm{a}, 1}$, Teresa Cunha-Oliveira ${ }^{\mathrm{a}, 1}$, Rui F. Simões ${ }^{\mathrm{a}}$, Filipa S. Carvalho ${ }^{\mathrm{a}}$, Ana Burgeiro ${ }^{\mathrm{a}}$, \\ Kendra Nordgren $^{\mathrm{b}}$, Kendall B. Wallace ${ }^{\mathrm{b}}$, Paulo J. Oliveira ${ }^{\mathrm{a}, *}$ \\ ${ }^{\text {a }}$ CNC-Center for Neuroscience and Cell Biology, University of Coimbra, UC Biotech Building, Biocant Park, 3060-197 Cantanhede, Portugal \\ ${ }^{\mathrm{b}}$ Department of Biomedical Sciences, University of Minnesota Medical School, Duluth, USA
}

\section{A R T I C L E I N F O}

\section{Keywords:}

Doxorubicin

Persistent cardiotoxicity

Mitochondria

Epigenetics

Gene expression

\begin{abstract}
A B S T R A C T
Doxorubicin (DOX), a potent and broad-spectrum antineoplastic agent, causes an irreversible, cumulative and dose-dependent cardiomyopathy that ultimately leads to congestive heart failure. The mechanisms responsible for DOX cardiotoxicity remain poorly understood, but seem to involve mitochondrial dysfunction on several levels. Epigenetics may explain a portion of this effect. Since mitochondrial dysfunction may affect the epigenetic landscape, we hypothesize that this cardiac toxicity may result from epigenetic changes related to disruption of mitochondrial function. To test this hypothesis, eight-week-old male Wistar rats (n $=6 /$ group) were administered 7 weekly injections with DOX $\left(2 \mathrm{mg} \mathrm{kg}^{-1}\right)$ or saline, and sacrificed two weeks after the last injection. We assessed gene expression patterns by qPCR, global DNA methylation by ELISA, and proteome lysine acetylation status by Western blot in cardiac tissue from saline and DOX-treated rats. We show for the first time that DOX treatment decreases global DNA methylation in heart but not in liver. These differences were accompanied by alterations in mRNA expression of multiple functional gene groups. DOX disrupted cardiac mitochondrial biogenesis, as demonstrated by decreased mtDNA levels and altered transcript levels for multiple mitochondrial genes encoded by both nuclear and mitochondrial genomes. Transcription of genes involved in lipid metabolism and epigenetic modulation were also affected. Western blotting analyses indicated a differential protein acetylation pattern in cardiac mitochondrial fractions of DOX-treated rats compared to controls. Additionally, DOX treatment increased the activity of histone deacetylases. These results suggest an interplay between mitochondrial dysfunction and epigenetic alterations, which may be a primary determinant of DOXinduced cardiotoxicity.
\end{abstract}

\section{Introduction}

Doxorubicin (Adriamycin ${ }^{\circledR}$, DOX) was one of the first anthracyclines to be isolated from strains of Streptomyces actinobacteria in the 1960s (Arcamone et al., 2000). Since its clinical introduction in the 1970s, DOX has remained one of the most frequently prescribed components in several currently used chemotherapy drug regimens for treating breast, ovarian and gastric carcinomas, sarcomas, leukemias, non-Hodgkin's and Hodgkin's lymphoma, multiple myeloma and many other cancers (Simunek et al., 2009; Sterba et al., 2013). The impact of anthracyclinebased therapies is particularly noteworthy in pediatric oncology, where the 5-year survival rate for childhood cancer has increased from around $30 \%$ in the 1960 s to over $70 \%$ in the modern era. Estimates are that over $50 \%$ of childhood cancer survivors have received some form of anthracycline treatment (Simunek et al., 2009; Sterba et al., 2013).

Despite having over 40 years of extensive clinical utilization, DOX mechanism of action remains a matter of controversy, as novel mechanisms are continuously being proposed. The cytostatic and cytotoxic actions of DOX in cancer cells have been attributed to various mechanisms, most often: 1) DNA intercalation, 2) topoisomerase II inhibition, 3) generation of free radicals with consequent induction of oxidative stress and 4) apoptosis induction - although the latter probably is an outcome, and not a cause of the aforementioned events (Gewirtz, 1999). Novel alternative mechanisms proposed include inhibition of DNA methylation enzymes (Yokochi and Robertson, 2004) and nucleosome destabilization induced by chromatin torsional stress (Yang et al., 2014). This array of antitumor mechanisms is likely to underlie the broad spectrum of therapeutic activity displayed by DOX.

\footnotetext{
* Corresponding author at: MitoXT (Mitochondrial Toxicology and Experimental Therapeutics Laboratory), Center for Neuroscience and Cell Biology, UC Biotech Building (Lote 8A), Biocant Park, 3060-197 Cantanhede, Portugal.

E-mail address: pauloliv@cnc.uc.pt (P.J. Oliveira).

${ }^{1}$ Authors contributed equally.
} 
As is the case for every anticancer agent, DOX is a double-edged sword due to its toxic side effects in healthy tissue - cardiac muscle, in particular. Administration of DOX commonly results in readily reversible short-term acute effects such as nausea, diarrhea, alopecia and electrocardiography alterations (Carvalho et al., 2009; Sterba et al., 2013). Chronic cardiotoxic effects, on the other hand, are of much greater concern. Cumulative doses exceeding $500-550 \mathrm{mg} / \mathrm{m}^{2}$ result in a clinically unacceptable risk of developing congestive heart failure (CHF) (Lefrak et al., 1973), thus severely limiting the clinical utility of this compound, which may persist until as many as 20 years after cessation of treatment (Steinherz et al., 1991).

The proposed mechanisms to account for this cardiomyopathy are as diverse as the aforementioned antineoplastic mechanisms (Carvalho et al., 2014), albeit entirely independent. Mitochondrial interactions are among the most commonly implicated and, consequently, best described mechanisms. DOX has been known to accumulate in cardiac mitochondrial membranes since the early 80s (Goormaghtigh et al., 1980; Nicolay et al., 1986; Peters et al., 1981). Since then, numerous studies have identified several forms of mitochondrial dysfunction and concomitant apoptotic signaling across various in vitro and in vivo experimental models (Carvalho et al., 2014). None of these studies, however, addressed the time course of events in the development of persistent cardiotoxicity.

As described above, DOX toxicity persists during an extended period of time (Steinherz et al., 1991). This phenomenon is characteristic of DOX cardiotoxicity, although it is mostly unexplored in the literature. Deleterious alterations in cardiac mitochondrial function, including oxygen consumption, free radical generation, decreased calcium loading capacity and altered mtDNA copy number and gene expression profile (within the studied time frame) (Berthiaume and Wallace, 2007; Richard et al., 2011; Serrano et al., 1999; Zhou et al., 2001), which again supports the notion that DOX toxicity in the myocardium is persistent and irreversible in nature. Clearly, long-term persistence of DOX cardiotoxicity has a large impact in survivors of childhood cancer (Bar et al., 2003), since it may lead to the appearance of later cardiac alterations during stressful events (including pregnancy) (Johnson et al., 1997).

Among the several hypotheses for this long-term DOX toxicity, the persistent alterations of gene expression in DOX-treated animals theory suggests that an epigenetic mechanism may be operating in promoting long-term DOX toxicity. Published data demonstrate that DOX causes a persistent and irreversible alteration of mitochondrial metabolism and gene expression (Berthiaume and Wallace, 2007; Richard et al., 2011). Interestingly, mitochondrial metabolism, as controlled by environment (i.e. nutrient availability) appears to have a critical role in the epigenomic landscape of nuclear DNA. When the energy supply is abundant, enzymes use mitochondrial-derived ATP and acetyl coenzyme A (Ac$\mathrm{CoA}$ ) to phosphorylate and acetylate chromatin, increasing gene expression. The opposite occurs when metabolism is decreased (Wallace and Fan, 2010). In other words, the notion that mitochondrial production of ATP, acetylcarnitine, and Ac-CoA directly impacts epigenetic regulation is a major framework for toxicological studies based on interference of mitochondrial bioenergetics. Toxicants that directly disturb mitochondrial function may deprive the accessibility of the nuclear DNA/histones to a source of acetyl groups and phosphate. In fact, DOX has been described to disturb creatine-phosphate shuttles (TokarskaSchlattner et al., 2006), as well as inhibit carnitine palmitoyl transferase I (CPT) and/or deplete its substrate L-carnitine (TokarskaSchlattner et al., 2006). Furthermore, DOX may also disturb the patterns of DNA/histone methylation. Depressed expression appears to be particularly focused on genes coding for enzymes participating in fatty acid beta-oxidation and mitochondrial ATP production (Berthiaume and Wallace, 2007), which suggests impaired mitochondrial Ac-CoA, acetylcarnitine, and ATP production. Furthermore, experiments using $\rho 0$ cells support the notion that mitochondrial metabolic integrity is a requirement for proper nuclear DNA methylation patterns (Smiraglia et al., 2008). Moreover, DOX cardiotoxicity in Wistar rats was decreased by co-administrating S-adenosylmethionine (SAM), the major biological methyl donor (Russo et al., 1994). All together, these studies strengthen the hypothesis that alterations of epigenetic landscape may occur during DOX toxicity through interference with cell and mitochondrial metabolism. The present paper aims to explore the involvement of crosstalk between mitochondrial dysfunction and epigenetics in long-term DOX cardiotoxicity. We hypothesize that alterations to the nuclear epigenetic landscape lead to long-term changes in gene expression and contribute to the long lasting mitochondrial toxicity manifested as decreased mitochondrial capacity and gene expression.

\section{Materials and methods}

\subsection{Animals and treatment protocol}

Animal handling was performed in accordance with the European Directive on the protection of animals used for scientific purposes (2010/63/EU). The procedures were approved by the CNC Committee for Animal Welfare and Protection. Male Wistar-Han rats were purchased form Charles River Laboratories (Barcelona, Spain) at 7 weeks of age and acclimated for one week in local animal house facilities (CNC Faculty of Medicine, University of Coimbra, Coimbra, Portugal). Two animals were housed per type III-H cage (Tecniplast, Italy) with irradiated corn cob grit bedding (Scobis Due, Mucedola, Italy) and environmental enrichment, maintained in controlled environmental requirements $\left(22^{\circ} \mathrm{C}, 45-60 \%\right.$ humidity, $15-20$ air changes/hour, $12 \mathrm{~h}$ artificial light/dark cycle, noise level $<55 \mathrm{~dB}$ ) and free access to standard rodent food (4RF21 GLP certificate, Mucedola, Italy) and $\mathrm{HCl}-$ acidified water ( $\mathrm{pH} 2.6)$.

Experimental manipulation was initiated with 8 weeks old rats weighing $220-260 \mathrm{~g}$. Animals were randomly assigned to one of two experimental groups: saline (SAL)-treated $(\mathrm{n}=6)$ and DOX-treated $(\mathrm{n}=6)$. Rats received seven weekly subcutaneous injections of DOX $\left(2 \mathrm{mg} \mathrm{kg}^{-1}\right)$, dissolved in normal saline $(0.9 \%[\mathrm{w} / \mathrm{v}] \mathrm{NaCl})$, or an equivalent volume of SAL solution. All animals were injected and weighed during the light phase of the cycle. Animals were euthanized by cervical dislocation followed by decapitation two weeks after the last injection (Supplementary Fig. S1). Unlike most previous subchronic DOX treatment works (Machado et al., 2010; Pereira et al., 2012, 2016; Serrano et al., 1999), we opted to provide one extra week after DOX treatment to allow for a better assessment of the long-term effects in the absence of the drug.

\subsection{RNA extraction and cDNA synthesis}

Total RNA was extracted from heart and liver tissue using the Aurum Total RNA Mini Kit (Bio-Rad, Hercules, CA, USA), according to the manufacturer's specifications. Thereafter, RNA quality and integrity was ascertained by visualization of the 28S/18S rRNA band pattern using an Experion Automated Electrophoresis System (Bio-Rad). Total RNA was quantified spectrophotometrically at A260 nm using a NanoDrop 2000 spectrophotometer (Thermo Scientific) and stored at $-80{ }^{\circ} \mathrm{C}$ until use. First-strand complementary DNA (cDNA) synthesis was performed using the iScript cDNA synthesis kit (Bio-Rad), according to the manufacturer's specifications.

\subsection{DNA extraction}

Total genomic DNA for mtDNA and m5C quantification was extracted from heart and liver tissue using the PureLink ${ }^{\mathrm{TM}}$ Genomic DNA Mini Kit (Invitrogen), according to the manufacturer's instructions. The extracted DNA samples were quantified spectrophotometrically at A260 nm using a NanoDrop 2000 spectrophotometer (Thermo Scientific, USA) and stored at $-80^{\circ} \mathrm{C}$ until use. 
Table 1

List of oligonucleotide primer sequences used for qPCR. Symbols and names are relative to the Rat Genome Database (RGD, http://rgd.mcw.edu/); accession numbers are relative to the GenBank ${ }^{\circ}$ database. For each primer, F and $\mathrm{R}$ indicate forward and reverse orientation, respectively.

\begin{tabular}{|c|c|c|c|}
\hline Target & Symbol & Accession no. & Sequence $\left(5^{\prime}-3^{\prime}\right)$ \\
\hline \multirow[t]{2}{*}{$18 \mathrm{~S}$} & Rn18s & NR_046237 & F ACTCAACACGGGAAACCTC \\
\hline & & & R ACCAGACAAATCGCTCCAC \\
\hline ACAA2 & & & R CCACCTCGACGCCTTAAC \\
\hline \multirow[t]{2}{*}{ ACC2 } & Acacb & NM_053922 & F ACAGCAAGAGCCTTCAAGAG \\
\hline & & & R CGCAGTCCGTAATCCACAA \\
\hline \multirow[t]{2}{*}{ ACL } & Acly & NM_016987 ${ }^{\mathrm{a}}$ & F GCTGCGTTACCAAGACACT \\
\hline & & & R AACTGGACCTCAGAAGAGAACA \\
\hline \multirow[t]{2}{*}{ ACOX1 } & Acox 1 & NM_017340 & F GCAGACAGCCAGGTTCTTGATG \\
\hline & & & R ACTCGGCAGGTCATTCAGGTAT \\
\hline \multirow[t]{2}{*}{ ATP8 } & Mt-atp8 & AC_000022 $2^{\mathrm{b}}$ & F TGCCACAACTAGACACATCCACAT \\
\hline & & & R GAGGGAGGTGCAGGAAAGGTT \\
\hline \multirow[t]{2}{*}{ CACT } & Slc25a20 & NM_053965 & F GGAGAACGGATCAAATGCTTACT \\
\hline & & & R GGCAGGAACATCTCGCAT \\
\hline \multirow[t]{2}{*}{ CBP } & Crebbp & NM_133381 & F GCACCCATGCCAACAACATT \\
\hline & & & R ACCTGGCCCTGTGAAACAC \\
\hline COX1 & & & R GCCGAAGAATCAGAATAGGTGTTG \\
\hline \multirow[t]{2}{*}{ Cyt b } & Mt-cyb & AC_000022 $2^{\mathrm{b}}$ & F TACGCTATTCTACGCTCCATTC \\
\hline & & & R GCCTCCGATTCATGTTAAGACTA \\
\hline Cyt c & Cycs & NM_012839 & F CTTGGGCTAGAGAGCGGGAC \\
\hline & & & R CCCATTTTAAATTCGGTCCGGG \\
\hline DNMT1 & Dnmt1 & NM_053354 & F GGAAGGTGAGCATCGACGAA \\
\hline & & & R TGCTGTGACCCTGGCTAGAT \\
\hline Ep300 & Ep300 & XM_001076610 & F TGGAGGCACTTTACCGACAG \\
\hline & & & R GATCCATGGGGCTCTTCACA \\
\hline HDAC1 & Hdac1 & NM_001025409 & F AGCCAAAGGGGTCAAAGAAGA \\
\hline & & & R TGAGAAATTGAGGGAAAGTAAGGGA \\
\hline HDAC2 & Hdac2 & NM_053447 & F GGAGGTCGTAGGAATGTCGC \\
\hline & & & R TTTGGCTCCTTTGGTGTCTGT \\
\hline HDAC3 & Hdac3 & NM_053448 & F CTGGGAGGTGGTGGTTACAC \\
\hline & & & R TCTGATTCTCGATGCGGGTG \\
\hline HDAC4 & Hdac4 & NM_053449 & F CATGGTTCAACGTTCATCTCTGC \\
\hline & & & R CGCAAACTCGAAGTCCCACT \\
\hline & & & R CCTGACATGCCATCCGACTC \\
\hline HDAC6 & Hdac6 & XM_001057931 & F CCCTACAGGAGGTGGAGTTG \\
\hline & & & R GCTCCTGGAACGGCTCTTT \\
\hline HDAC7 & Hdac7 & XM_001059057 & F GACAAGAGCAAGCGAAGTGC \\
\hline & & & R ACTGTTCTCTCAAGGGCTGC \\
\hline HDAC8 & Hdac8 & NM_001126373 & F GTGCTGGAAATCACGCCAAG \\
\hline & & & R CACATGCTTCAGATTCCCTTTGA \\
\hline HDAC9 & Hdac9 & NM_001200045 & F AAACCCAGCATCTGACCTCCA \\
\hline & & & R CTGATTTCACGTCCACTGAGCTG \\
\hline HDAC10 & Hdac10 & NM_001035000 & F GCCCATAGAGGTCAGAGGAGA \\
\hline & & & R AGGCTAAGGGCAGTACCAGA \\
\hline MAT2a & Mat2a & NM_134351 & F GGGGAAGGTCATCCAGATAAGA \\
\hline & & & R AGCAACAGTTTCACAAGCCAC \\
\hline ND1 & Mt-nd1 & AC_000022 $2^{\mathrm{b}}$ & F TCCTCCTAATAAGCGGCTCCTTCT \\
\hline & & & R TGGTCCTGCGGCGTATTCG \\
\hline ND6 & Mt-nd6 & AC_000022 $2^{\mathrm{b}}$ & F TCCTCAGTAGCCATAGCAGTTGT \\
\hline & & & R GTTGTCTAGGGTTGGCGTTGAA \\
\hline NDUFA9 & Ndufa9 & NM_001100752 & F GAGAAGCAAGGCAGTGGGAGAG \\
\hline & & & R ACGAGAGGCACAGCAAGAAACC \\
\hline NRF-1 & Nrf1 & NM_001100708 & F CCAAGCATTACGGACCATAGTT \\
\hline & & & R CAGTACCAACCTGGATGAGC \\
\hline NRF-2 $\alpha$ & Gabpa & NM_001108841 & F CGGCACCAAGCATATCAC \\
\hline & & & R GGACCACTGTATAGGATCATAGG \\
\hline NRF-2 $\beta$ & Gabpb1 & NM_001039036 & F GCACCGCTGTCATTTTGTCG \\
\hline & & & R CAGAGCAGTCTCACGTCCTC \\
\hline PCAF & Pcaf & XM_003750617 & F CAGGTCAAGGGCTATGGAACC \\
\hline & & & R CCCATCAAAGTGGCTCCTTCA \\
\hline PGC-1 $\alpha$ & Ppargc1a & NM_031347 & F TGAGAAGCGGGAGTCTGAAAG \\
\hline & & & R AACCATAGCTGTCTCCATCATCC \\
\hline $\mathrm{POL} \gamma$ & Polg & NM_053528 & F ATAATGGCCCACACCCGTTT \\
\hline & & & R GAGTTTCCGGTACCACCCAG \\
\hline PPAR $\alpha$ & Ppara & NM_013196 & F AGACTAGCAACAATCCGCCTTT \\
\hline & & & R TGGCAGCAGTGGAAGAATCG \\
\hline SDHA & Sdha & NM_130428 & F CTATGGAGACCTACAGCATCT \\
\hline & & & R AATCCGCACCTTGTAATCTTC \\
\hline TAZ & Taz & NM_001025748 & F CAAATGGGGAATTGGACGGC \\
\hline & & & R AGGGAGTGTACTGAAGGGCT \\
\hline TBP & Tbp & NM_001004198 & F ССТАТСАСТССТGCСАСАCС \\
\hline
\end{tabular}


Table 1 (continued)

\begin{tabular}{|c|c|c|c|}
\hline Target & Symbol & Accession no. & Sequence $\left(5^{\prime}-3^{\prime}\right)$ \\
\hline & & & R CAGCAAACCGCTTGGGATTA \\
\hline TFAM & Tfam & NM_031326 & F AATGTGGGGCGTGCTAAGAA \\
\hline \multirow[t]{2}{*}{ UQCRC1 } & Uqcrc1 & NM_001004250 & F GAGACACAGGTCAGCGTATTG \\
\hline & & & R TTTGTTCCCTTGAAAGCCAGAT \\
\hline \multirow[t]{2}{*}{ UQCRFS1 } & Uqcrfs1 & NM_001008888 & F GGACGTGAAGCGACCCTT \\
\hline & & & R CGAACAGAAGCAGGAACATTCAG \\
\hline$\beta_{2} \mathrm{M}$ & & & R CGACCGCACACTATAGGGAC \\
\hline \multirow[t]{2}{*}{$\beta$-actin } & Actb & NM_031144 & F AGATCAAGATCATTGCTCCTCCT \\
\hline & & & R ACGCAGCTCAGTAACAGTCC \\
\hline
\end{tabular}

\footnotetext{
${ }^{\text {a }}$ Amplifies other transcript variants.

${ }^{\mathrm{b}}$ Reference sequence for the complete Wistar strain mitochondrial genome.

${ }^{c}$ Gene ID.
}

\subsection{Quantitative PCR}

Quantitative real-time PCR (qPCR) was performed in duplicated reactions, each comprising $12.5 \mathrm{ng}$ of either cDNA or DNA, $500 \mathrm{nM}$ of each gene-specific primer (Table 1) and $1 \times$ SsoFast EvaGreen Supermix (Bio-Rad), made up to $10 \mu \mathrm{L}$ with nuclease-free water. Reactions were performed in sealed 96-well plates and monitored with a CFX96 ${ }^{\mathrm{TM}}$ Real-Time PCR Detection System (Bio-Rad). Results were analyzed using the CFX Manager ${ }^{\mathrm{TM}} 3.1$ software (Bio-Rad). For gene expression analyses, reactions were performed with the following cycling parameters: $95{ }^{\circ} \mathrm{C}$ for $30 \mathrm{~s}$, followed by 40 cycles of $95{ }^{\circ} \mathrm{C}$ for $5 \mathrm{~s}$ and $60-63{ }^{\circ} \mathrm{C}$ for $5 \mathrm{~s}$. To confirm the absence of genomic DNA contamination, a negative control was included in the reverse transcriptase reaction (NRT). Genomic DNA contamination was considered insignificant when the cycle threshold difference between the no-reverse transcriptase and the respective sample was above 10 cycles. Transcript levels analyzed by relative quantification using the Pfaffl method (Pfaffl, 2001), and normalized to the average expression of three reference genes (18S [Rn18s], TBP [Tbp] and $\beta$-actin [Actb]) (Vandesompele et al., 2002), which was shown to be stable between experimental conditions.

For mtDNA copy number quantification, reactions were performed with the following cycling parameters: $98^{\circ} \mathrm{C}$ for $2 \mathrm{~min}$, followed by 40 cycles of $98^{\circ} \mathrm{C}$ for $5 \mathrm{~s}$ and $63^{\circ} \mathrm{C}$ for $5 \mathrm{~s}$. Levels of the mitochondrial COX1 (Mt-co1) gene were normalized relative to the levels of the singlecopy nuclear $\beta 2 \mathrm{M}$ gene, corrected to the diploid genome, also using the Pfaffl method. For all reactions, amplification of a single PCR product was confirmed by melt curve analyses and PCR product $2 \%$ agarose gel electrophoresis at the end of every experiment.

\subsection{Mitochondrial DNA integrity}

Mitochondrial DNA integrity was evaluated with a PCR-based assay adapted from Bliksoen et al. (2015) and Kovalenko and Santos (2009). Two separate PCR reactions were performed - one amplifying a long $10,821 \mathrm{bp}(\sim 10 \mathrm{~kb})$ fragment of mtDNA and the other amplifying a short $121 \mathrm{bp}$ fragment of mtDNA. For the $10 \mathrm{~kb}$ fragment, primer sequences used were the forward and reverse primers of the ND1 (Mtnd1) and ND6 (Mt-nd6) targets, respectively (see Table 1). PCR was performed in reactions comprising $50 \mathrm{ng}$ of total DNA, $500 \mathrm{nM}$ of each primer and $1 \times$ Phusion $^{\mathrm{TM}}$ Hot Start II High-Fidelity PCR Master Mix (Thermo Scientific), made up to $25 \mu \mathrm{L}$ with nuclease-free water, under the following cycling parameters: $98^{\circ} \mathrm{C}$ for $2 \mathrm{~min}, 98^{\circ} \mathrm{C}$ for $10 \mathrm{~s}, 68^{\circ} \mathrm{C}$ for $20 \mathrm{~s}, 72^{\circ} \mathrm{C}$ for $5 \mathrm{~min} 45 \mathrm{~s}$, followed by a final elongation step at $72{ }^{\circ} \mathrm{C}$ for $7 \mathrm{~min} 30 \mathrm{~s}$. For the $121 \mathrm{bp}$ fragment, primer sequences used were the forward and reverse primers of the COX1 target (see Table 1). PCR was performed in reactions comprising $50 \mathrm{ng}$ of total DNA, $500 \mathrm{nM}$ of each primer and $1 \times$ HotStarTaq Master Mix (Qiagen, Germany), made up to $25 \mu \mathrm{L}$ with nuclease-free water, under the following cycling

parameters: $95{ }^{\circ} \mathrm{C}$ for $2 \mathrm{~min}, 94^{\circ} \mathrm{C}$ for $10 \mathrm{~s}, 63{ }^{\circ} \mathrm{C}$ for $30 \mathrm{~s}, 72{ }^{\circ} \mathrm{C}$ for $1 \mathrm{~min}$, followed by a final elongation step at $72{ }^{\circ} \mathrm{C}$ for $10 \mathrm{~min}$.

\subsection{Determination of global DNA 5mC content by ELISA}

The m5C content of total DNA from heart and liver tissue was determined using the fluorometric EpiSeeker Methylated DNA Quantification Kit (Abcam; ab117129), according to the manufacturer's instructions. Briefly, $100 \mathrm{ng}$ of DNA were bound to the provided assay wells, incubated for $60 \mathrm{~min}$ with capture antibody and then for $30 \mathrm{~min}$ with detection antibody. After incubating the probed DNA with the provided substrate for $4 \mathrm{~min}$, methylated DNA was quantified fluorimetrically by reading the fluorescence at $\lambda \mathrm{Ex} / \lambda \mathrm{Em}=544 / 590 \mathrm{~nm}$ in a Victor X3 multilabel plate reader (PerkinElmer). Results were expressed as percent $\mathrm{m} 5 \mathrm{C}$, calculated using a linear regression equation generated with controls provided in the kit.

\subsection{Subcellular fractionation}

Subcellular fractions for Western blotting analyses were obtained from cardiac ventricular and liver tissue according to the method described by Dimauro et al. (2012), with slight modifications. Excised tissue was weighed, rinsed with PBS, resuspended in ice-cold STM buffer (50 mM Tris-HCl [pH 7.4], $250 \mathrm{mM}$ sucrose, $50 \mathrm{mM} \mathrm{MgCl}_{2}$; supplemented freshly with $1 \mathrm{mM}$ dithiothreitol (DTT), $1 \mu \mathrm{L} \mathrm{mL}^{-1}$ protease inhibitor cocktail (PIC; Sigma-Aldrich, Barcelona, Spain; \#P8340), $5 \mathrm{mM}$ nicotinamide (NAM) and $5 \mathrm{mM}$ sodium butyrate (SB) and homogenized on ice in a pre-cooled Potter-Elvehjem glass homogenizer using a tight-fitting Teflon pestle attached to a mechanical overhead stirrer (Heidolph, Germany) set to $600 \mathrm{rpm}$ for 50-60 strokes. The homogenate was decanted into a microcentrifuge tube and maintained on ice for $15 \mathrm{~min}$, vortexed at maximum speed for $15 \mathrm{~s}$, and centrifuged at $800 \mathrm{~g}$ for $15 \mathrm{~min}$ at $4{ }^{\circ} \mathrm{C}$. The supernatant was labeled as S1 and used for concurrent extraction of cytosolic and mitochondrial fractions. The pellet was washed thrice with centrifugation steps after resuspension in STM buffer. The washed pellet was then resuspended in NEH buffer (0.5 M NaCl, 0.2 mM EDTA, 20 mM HEPES, pH 7.9, $1.5 \mathrm{mM}$ $\mathrm{MgCl}_{2}, 20 \%[\mathrm{v} / \mathrm{v}$ ] glycerol, $1 \%$ [v/v] Triton X-100; supplemented as before), vortexed at maximum speed for $15 \mathrm{~s}$ and maintained on ice for $30 \mathrm{~min}$. Nuclei were lysed with sonication $(3 \times$ in $10 \mathrm{~s}$ bursts $)$ in a water bath sonicator with $30 \mathrm{~s}$ pauses between sonication steps whilst keeping on ice throughout. The lysate was centrifuged for $30 \mathrm{~min}$ at $9000 \mathrm{~g}$ and the resulting supernatant (the nuclear fraction) was stored at $-80{ }^{\circ} \mathrm{C}$ until use. Concurrently, cytosolic and mitochondrial fractions were obtained from the supernatant $\mathrm{S} 1$ by centrifugation at $800 \mathrm{~g}$ for $10 \mathrm{~min}$, so as to remove any remaining nuclear contamination. If the nuclear pellet P2 was substantial, it was resuspended in STM buffer and combined with the pellet P1.1. The supernatant S2 containing the cytosolic and mitochondrial fractions was centrifuged for $10 \mathrm{~min}$ at 
$11,000 \mathrm{~g}$, the supernatant S3 was precipitated in cold $80 \%$ acetone supplemented with $1 \mathrm{M} \mathrm{NaCl}$ at $-20^{\circ} \mathrm{C}$ for $1 \mathrm{~h}$ (Crowell et al., 2013) and subsequently centrifuged for $10 \mathrm{~min}$ at $11,000 \mathrm{~g}$. The resulting pellet P4 (the cytosolic fraction) was resuspended in STM buffer and stored at $-80{ }^{\circ} \mathrm{C}$ until use. The mitochondrial pellet P3.1 was washed once with a centrifugation step after resuspension in STM buffer, the washed pellet was then resuspended in Tris-EDTA with Triton X-100 (TE-TX-100) buffer (50 mM Tris-HCl [pH 6.8], 1 mM EDTA, 0.5\% [v/v] Triton X-100; supplemented as before), sonicated as before, and stored at $-80{ }^{\circ} \mathrm{C}$ until use. Nuclear fractions for enzymatic activity assays were obtained from heart and liver tissue as described above, but with the omission of buffer supplementation. Protein content of all extracts was determined by the BCA assay, calibrated with bovine serum albumin.

\subsection{Western blotting}

Subcellular fractions from ventricular heart tissue, obtained as described above, were denatured in Laemmli sample buffer at $95{ }^{\circ} \mathrm{C}$ for $5 \mathrm{~min}$. Equivalent amounts of protein $(15 \mu \mathrm{g})$ were ran in SDS-PAGE gels under reducing conditions. The separated proteins were electrotransferred onto PVDF membranes (Millipore, USA). After transfer, the PVDF membranes were incubated in Ponceau $S$ staining solution $(0.1 \%$ $[\mathrm{w} / \mathrm{v}]$ in $5 \%[\mathrm{v} / \mathrm{v}]$ acetic acid) for $1 \mathrm{~min}$, followed by destaining in distilled water to remove non-specific Ponceau $S$ staining. The membranes were then inserted in between transparency sheets and imaged using a BioSpectrum 500 imaging system (UVP). After destaining in Tris-buffered saline with Tween (TBS-T: $10 \mathrm{mM}$ Tris-HCl [pH 7.4], $150 \mathrm{mM} \mathrm{NaCl}$ and $0.05 \%$ [v/v] Tween 20), membranes were blocked with $5 \%$ fat-free milk (Bio-Rad) in TBS-T for $1 \mathrm{~h}$ at room temperature and then incubated with anti-acetyl-lysine (Ac-Lys) antibody (1:1000; Cell Signaling Technology; \#9441) at $4{ }^{\circ} \mathrm{C}$ overnight. Membranes were then washed with TBS-T and incubated for $2 \mathrm{~h}$ at $4{ }^{\circ} \mathrm{C}$ with alkaline phosphatase (AP)-conjugated goat anti-rabbit IgG (1:5000; Santa Cruz Biotechnology; sc-2007). After a final wash in TBS-T, immunoreactive proteins were detected by membrane exposure to the enhanced chemifluorescence (ECF) reagent (GE Healthcare, Piscataway, NJ, USA) followed by imaging with a BioSpectrum 500 imaging system (UVP). Quantification by densitometric scanning was normalized to protein levels determined by Ponceau S staining (Romero-Calvo et al., 2010).

\subsection{HAT and HDAC activity assay}

Histone acetyltransferase (HAT) activity in cardiac and liver tissue was measured using the colorimetric Histone Acetyltransferase Assay Kit (Abcam; ab65352), according to the manufacturer's instructions. Briefly, $25 \mu \mathrm{g}$ of nuclear extract were incubated with HAT substrates I and II and NADH-generating enzyme in assay buffer for $2 \mathrm{~h}$ at $37^{\circ} \mathrm{C}$. Absorbance was measured at $440 \mathrm{~nm}$ using a Cytation ${ }^{\mathrm{TM}} 3$ microplate reader (BioTek, USA). Histone deacetylase (HDAC) activity in cardiac tissue was measured using the fluorimetric Histone Deacetylase Activity Assay Kit (Abcam; ab156064), according to the manufacturer's instructions. The specificity of the assay was ascertained with negative controls containing trichostatin A - a selective inhibitor of class I and II HDACs. Briefly, $25 \mu \mathrm{g}$ of nuclear extract were incubated with the substrate peptide and endopeptidase in assay buffer for $30 \mathrm{~min}$ at room temperature. Fluorescence was measured at $\lambda \mathrm{Ex} / \lambda \mathrm{Em}=355 / 460 \mathrm{~nm}$ using a Cytation ${ }^{\mathrm{TM}} 3$ microplate reader (BioTek, USA).

\subsection{Statistical analysis}

All data are expressed as mean \pm SEM. The normality of distributions and the homogeneity of variances were objectively evaluated by the Shapiro-Wilk test and the F-test, respectively. Comparisons between two groups were performed using the Student $t$-test, the Welch $t$ test or the Mann-Whitney $U$ test, as indicated in the corresponding table and figure legends. A two-sided $\mathrm{p}<0.05$ was considered statistically significant. All statistical analyses were performed using the $\mathrm{R}$ v. 3.1.2 statistical software environment.

\section{Results}

\subsection{Body, heart and liver weight}

Rats were administered seven weekly injections of saline solution or DOX $\left(2 \mathrm{mg} \mathrm{kg}^{-1}\right)$ and sacrificed two weeks following the last injection. All but one animal survived the entire treatment protocol. DOX-treated rats weighed significantly less than control rats at sacrifice (14\% less; Supplementary Table S1). No significant changes in either heart or liver weight were observed between the two treatment groups (Supplementary Table S1). Therefore, the increase in organ:body ratios seen in DOX-treated animals reflected a change in body mass rather than alterations in organ mass (Supplementary Table S1).

\subsection{DOX alters mitochondrial biogenesis}

Subchronic DOX treatment is known to alter cardiac mitochondrial function (Marques-Aleixo et al., 2015; Pereira et al., 2012, 2016; Serrano et al., 1999; Solem et al., 1996). To assess if alterations to the mitochondrial biogenesis transcriptome could play a role in mitochondrial alteration, we measured the levels of transcripts of a number of genes involved in this process, including peroxisome proliferator-activated (PPAR) receptor gamma coactivator 1-alpha (PGC$1 \alpha$ ), the master regulator of mitochondrial biogenesis, and its main downstream transcription factors (nuclear respiratory factors [NRF] -1 and -2) (Scarpulla, 2011). Subchronic DOX treatment decreased the transcript levels for PGC-1 $\alpha$ (Ppargc1a), but did not affect NRF-1 (Nrf1) and the alpha subunit of NRF-2 (NRF-2 $\alpha$ [Gabpa]) mRNAs. In contrast, NRF-2 $\beta$ (Gabpb1) mRNA was significantly increased (Fig. 1A). Because mtDNA transcription is paramount to functional mitochondrial biogenesis, we subsequently measured the transcripts encoding for proteins that control mtDNA transcription, integrity and replication; namely mitochondrial transcription factor A (TFAM) and DNA polymerase $\gamma$ (POL $\gamma)$. Transcript levels for TFAM (Tfam) were decreased in DOX-treated rats; however, the expression of POL $\gamma$ (Polg) was unaffected (Fig. 1A). Increases in mitochondrial mass also involve the biosynthesis of mitochondrial membranes, which in turn requires de novo synthesis of cardiolipin, the main functional phospholipid of the mitochondrial inner membrane. Tafazzin (TAZ) is a transacylase required for cardiolipin metabolism that has been implicated in a number of mitochondrial disorders that culminate in cardiomyopathy (Schlame and Ren, 2006). DOX treatment induced a small, although statistically significant decrease in TAZ (Taz) mRNA levels (Fig. 1A). A possible consequence of TFAM downregulation is a decrease in mtDNA quality and quantity. Indeed, in addition to its role as a mitochondrial transcription factor, TFAM is also a major component of the nucleoid - a mitochondrial maintenance structure (Campbell et al., 2012). Moreover, steady-state levels of TFAM and mtDNA display a strong correlation (Campbell et al., 2012). We therefore assessed the copy number and integrity of mtDNA. Subchronic DOX treatment significantly decreased the copy numbers of the mitochondrial COX1 gene per nuclear $32 \mathrm{M}$ gene in heart but not liver tissue (Fig. 1B), suggesting a decreased mtDNA copy number specifically in the heart. There was no significant difference in the integrity of mtDNA extracted from heart, suggesting that there is an equal extent, if any, of mtDNA single- and double-strand break damage between both groups (Fig. 1C). Finally, as a possible outcome of the above-mentioned effects, we evaluated transcripts for the various components of the OxPhos machinery encoded by either the nuclear or the mitochondrial genomes (Fig. 1D). We observed a general trend towards a decrease in most of the transcripts assessed, most notably in two nDNA-encoded complex III subunits (UQCRC1 [Uqcrc1] and UQCRFS1 [Uqcrfs1]), one mtDNA- encoded complex I subunit 
A

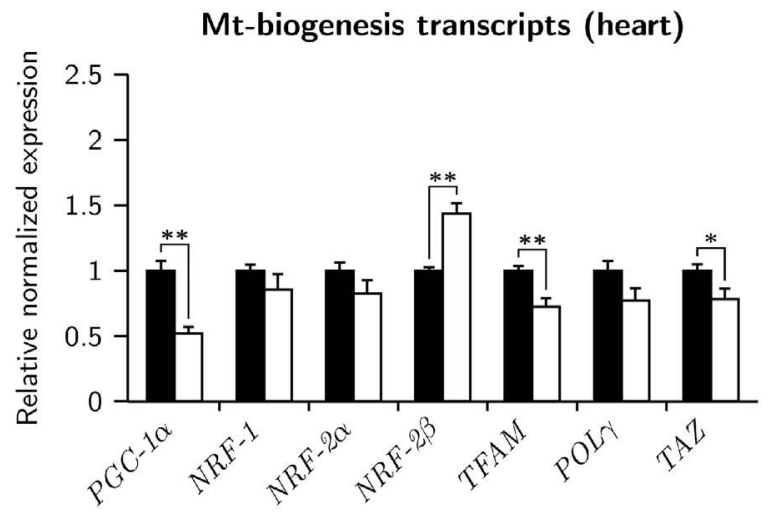

B

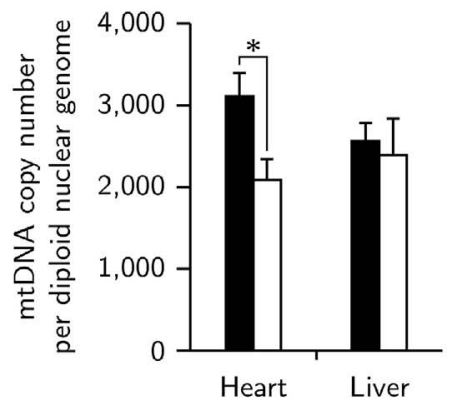

Fig 1. DOX compromised mitochondrial biogenesis transcriptomics and mitoepigenomics. (A) Heart mRNA levels of (A) genes involved in the regulation of mitochondrial maintenance and biogenesis and (D) nuclear and mitochondrial genes encoding OxPhos subunits were quantified by qPCR and normalized to $18 \mathrm{~S}$, TBP and $\beta$-actin ( $\mathrm{n}=4-5$ per group). (B) mtDNA copy number was measured by qPCR ( $n=3-5$ per group). (C) mtDNA integrity was examined by a PCR-based assay as described $(n=5$ per group). Representative gels are shown with the $10 \mathrm{~kb}$ and $121 \mathrm{bp}$ products. *p $<0.05$ and $* * \mathrm{p}<0.01$ for the indicated comparisons. The posthoc tests were the Mann-Whitney $U$ test for mtDNA quantification (heart) and the Student's $t$-test for mtDNA quantification (liver) and mtDNA damage (heart \& liver). Data are presented as mean \pm SEM.

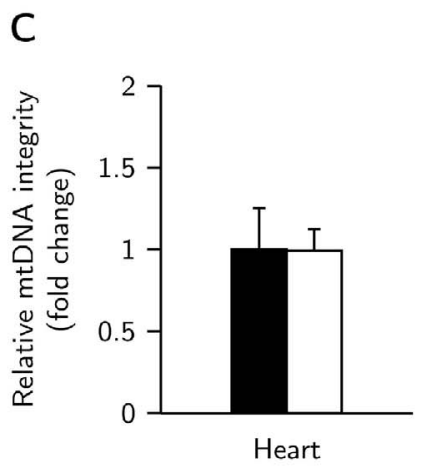

$10 \mathrm{~kb}$
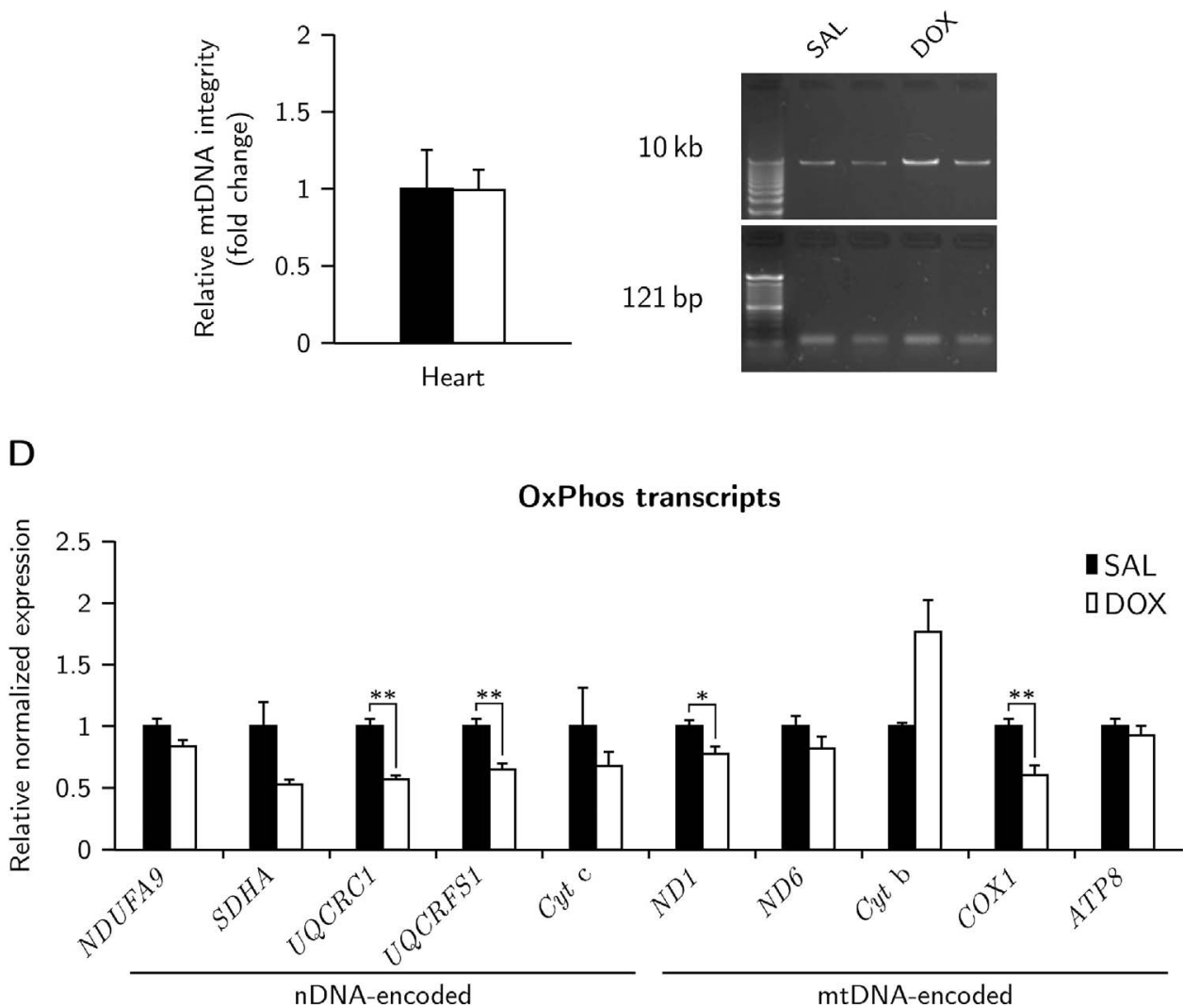

(ND1) and one mtDNA-encoded complex IV subunit (COX1). Curiously, there was a trend towards upregulation of Cyt b (Mt-cyb) mRNA, similarly observed by our group in a very similar subchronic toxicity model (Pereira et al., 2016).

\subsection{DOX alters acetyl CoA metabolism and transport transcripts and changes mitochondrial protein acetylation patterns}

Subchronic DOX treatment has previously been reported to decrease the expression of proteins involved in the fatty acid $\beta$-oxidation pathway (Berthiaume and Wallace 2007). To confirm this effect in our model, we measured the transcripts for PPAR $\alpha$, which regulates the transcriptional activation or repression of genes encoding for enzymes in free fatty acid (FFA) metabolism (Finck 2007; Munday and Hemingway, 1999), as well as transcripts for enzymes involved in fatty acid $\beta$-oxidation (Fig. 2A). We observed a marked decrease in transcripts for PPAR $\alpha$ (Ppara) and for both $\beta$-oxidation enzymes assessed
(ACOX1 [Acox1], ACAA2 [Acaa2]). Interestingly, transcripts for AcCoA carboxylase 2 (ACC2 [Acacb]), which is repressed by PPAR $\alpha$ (Munday and Hemingway 1999), were also found to be decreased. Transcripts for CACT (Scl25a20), but not ACL (Acly) were also decreased, suggesting that carnitine-mediated transport of acetyl moieties between the mitochondrial and cytosolic compartments may be impaired.

To test whether these findings were relevant for protein acetylation levels and patterns, we carried out Western blot analyses of total Ac-Lys content in three different subcellular fractions - nuclear, mitochondrial and cytosolic - to increase the spatial resolution of our findings. Total protein acetylation levels were unchanged in all the three assessed subcellular fractions (Fig. 2B-D). Protein acetylation patterns, however, were found to be altered in mitochondrial fractions. SAL treated rats displayed inconsistent levels of a $\approx 63 \mathrm{kDa}$ acetylated protein band in mitochondrial fractions, which was found to be present in three out of five animals. In all cardiac samples from DOX-treated rats, however, 
A

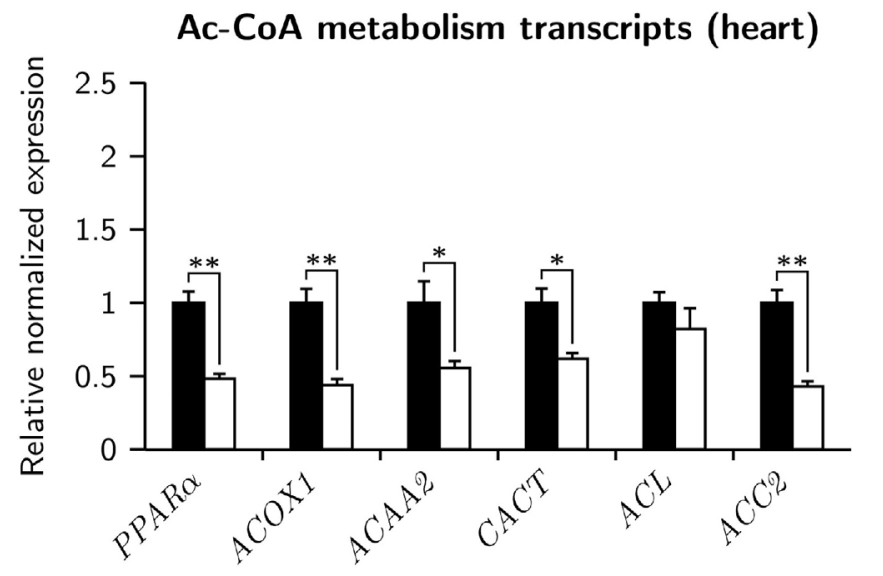

Fig. 2. DOX altered the levels of transcripts of genes involved in the metabolism and availability of AcCoA in cardiac tissue, but did not change total lysine acetylation patterns. (A) Heart mRNA levels of genes involved in the metabolism and transport of acetyl units were quantified by $\mathrm{qPCR}$ and normalized to $18 \mathrm{~S}, \quad$ TBP and $\beta$-actin $\quad(\mathrm{n}=4-5)$. (B-D) Representative immunoblots of western blot experiments showing relative levels of proteins acetylated at Lys residues of (B) nuclear fractions, (C) mitochondrial fractions and (D) cytosolic fractions extracted from cardiac tissue. The arrow points to a band that is absent in DOX-treated samples.

$* \mathrm{p}<0.05$ and ${ }^{* *} \mathrm{p}<0.01$ for the indicated comparisons. The post-hoc tests were the Student's $t$-test or the Welch's $t$-test, for datasets with homogenous or heterogeneous variances, respectively. Data are presented as mean \pm SEM.
B

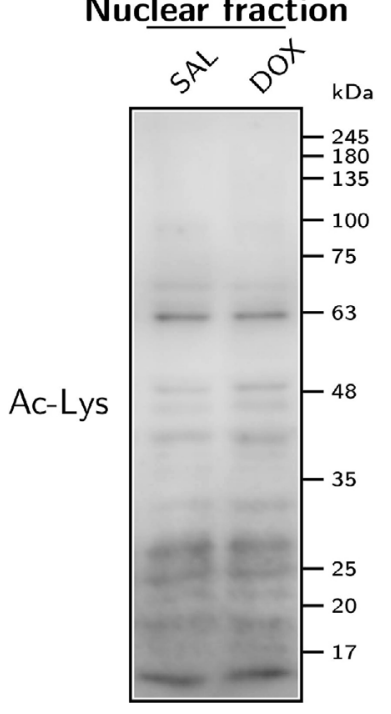

C
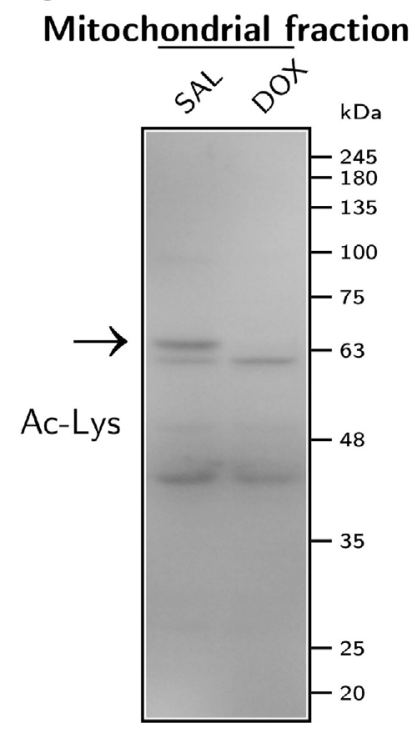

D

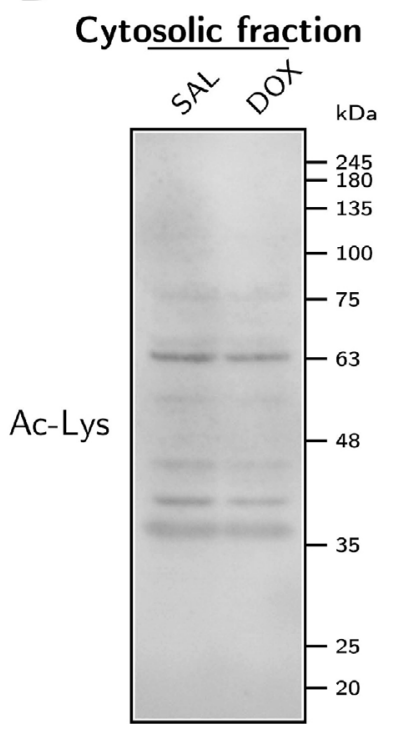

this band was completely absent (Fig. 2C).

\subsection{DOX alters the transcription and activity of histone modulators}

Histone modification by HATs and HDACs is one of the major mechanisms of transcriptional regulation. The levels of these enzymes not only dictate the steady state equilibrium of histone acetylation, but also determine the availability of these factors to be recruited to transcriptional regulatory complexes (Kouzarides, 2007). Because of their role in modulating the epigenome, we next verified whether transcripts from genes encoding HATs (CBP [Crebbp], Ep300, PCAF [Pcaf]) and HDACs (HDAC1-10 [Hdac1-10]) were altered by DOX treatment. Two of the three HATs mRNAs assessed, CBP and Ep300, were significantly downregulated in DOX-treated animals (Fig. 3A). Most of the targeted transcripts encoding for HDACs displayed a trend towards downregulation, with a notable exception of HDAC1 (Hdac1), which was found to be increased in DOX-treated animals (Fig. 3A). We next investigated the activities of these two sets of enzymes. Histone acetyltransferase activity was found to be unaffected by DOX treatment in both heart and liver tissue; however, HDAC activity was increased in heart tissue (Fig. 3B, C).

\subsection{DOX alters SAM metabolism transcripts and decreases global DNA $m 5 \mathrm{C}$ levels in cardiac tissue}

Maintenance of DNA methylation patterns is likely to depend on the levels of DNMT1 and its required substrate SAM, the synthesis of which requires the enzyme MAT2a (Lu and Mato, 2012). Subchronic DOX treatment decreased MAT2a (Mat2a) transcripts, thus suggesting an impairment in the synthesis of SAM. However, levels of DNMT1 (Dnmt1) were unaltered after DOX treatment (Fig. 4A). To assess whether DOX treatment affects DNA methylation in both heart and liver tissue, total DNA extracted from both tissues was analyzed with a m5C ELISA-based assay. DOX treatment resulted in a significant decrease in DNA methylation in heart but not in liver tissue (Fig. 4B).

\section{Discussion}

Mitochondrionopathy is a well-established early feature of DOX treatment (Wallace, 2003), however its role in the persistent, late-onset nature of DOX-induced cardiotoxicity remains elusive (Berthiaume and Wallace 2007). It is not yet clear whether the decline in cardiac metabolic function is due to compromised mitochondrial integrity and function, or rather due to a reprogramming of the cardiac metabolic profile via upstream events. The results from our study lend credibility to the hypothesis that chronologically links both aforementioned 
A

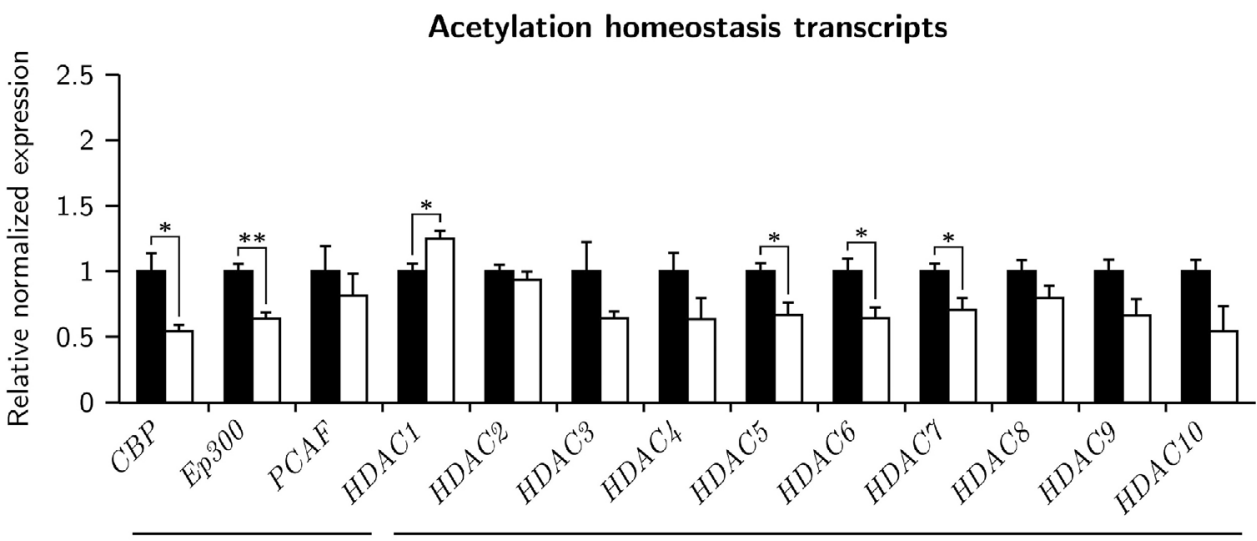

HATs

B

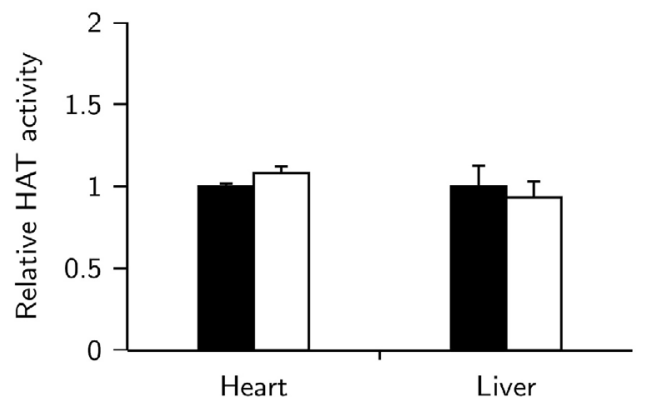

C

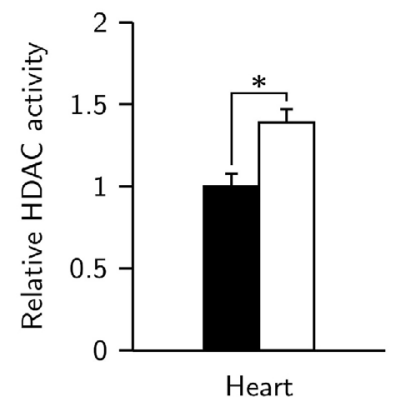

Fig. 3. DOX altered the levels of transcripts and activity of histone modifiers. (A) Heart mRNA levels of genes involved in histone acetylation and deacetylation were quantified by $\mathrm{qPCR}$ and normalized to $18 \mathrm{~S}$, TBP and $\beta$-actin ( $\mathrm{n}=4-5)$. (B, C) The activities of (B) HATs and (C) HDACs were measured using commercial kits as described in Materials and Methods $(\mathrm{n}=4-5)$. ${ }^{*} \mathrm{p}<0.05$ and ${ }^{* *} \mathrm{p}<0.01$ for the indicated comparisons. The post-hoc tests were the Student's $t$-test or the Welch's $t$-test, for datasets with homogenous or heterogeneous variances, respectively. Data are presented as mean \pm SEM. events. Specifically, we propose that DOX initially disturbs the mitochondrial-dependent production of the main acetyl and methyl donors (Ac-CoA and SAM, respectively) and subsequently imprints a long lasting toxic epigenetic memory that manifests itself through an aberrant metabolic transcriptome and metabolome (Carvalho et al., 2010; Berthiaume and Wallace 2007). Herein we provide a description of the initial events relevant to our hypothesis that are taking place shortly after a subchronic DOX treatment.

As previously mentioned, disruption of mitochondrial function and biogenesis is widely acknowledged as a key component in DOX-induced cardiotoxicity (Octavia et al., 2012; Wallace 2003). Indeed, strategies aimed at increasing mitochondrial biogenesis, such as treatment with resveratrol, endurance training and stimulation of the $\mathrm{CO} / \mathrm{hemeox}$ ygenase $(\mathrm{CO} / \mathrm{HO})$ system, have shown to be effective in diminishing cardiac DOX toxicity (Ascensao et al., 2005; Danz et al., 2009; Suliman et al., 2007). Mitochondrial function is heavily dependent on a coordinated transcriptional regulation of both the nuclear and the mitochondrial genomes (Scarpulla, 2006). The coactivator PGC-1 $\alpha$ has emerged as a key component in the orchestration of mitochondrial biogenesis and is highly expressed in tissues with high oxidative activity such as the heart (Ventura-Clapier et al., 2008). PGC-1 $\alpha$ is a coactivator of the transcription factors NRF-1 and -2 that in turn promote the expression of TFAM, thus establishing a concerted activation of the nuclear and mitochondrial genomes. In the present study, we demonstrate that subchronic DOX treatment significantly decreases PGC- $1 \alpha$ transcripts, as well as of its downstream target TFAM.

Previous reports in the literature show that DOX decreases the content of both PGC-1 $\alpha$ and TFAM (Che et al., 2015; Guo et al., 2014; Suliman et al., 2007). Decreased levels of PGC-1 $\alpha$ and TFAM would be in agreement with the depression in nuclear- and mitochondrial-encoded OxPhos transcripts in DOX-treated rats that we observed.

Another key index of mitochondrial biogenesis, or alterations thereof, is cellular mtDNA content. Our results show that DOX treatment decreases the mtDNA:nDNA copy number in cardiac tissue, which may also be implicated in the observed depression of mitochondrialencoded OxPhos transcripts. Interestingly, we did not observe
A

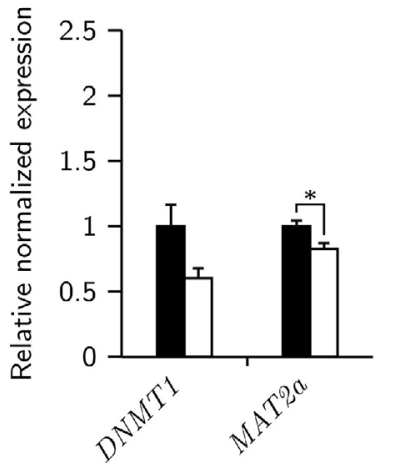

B

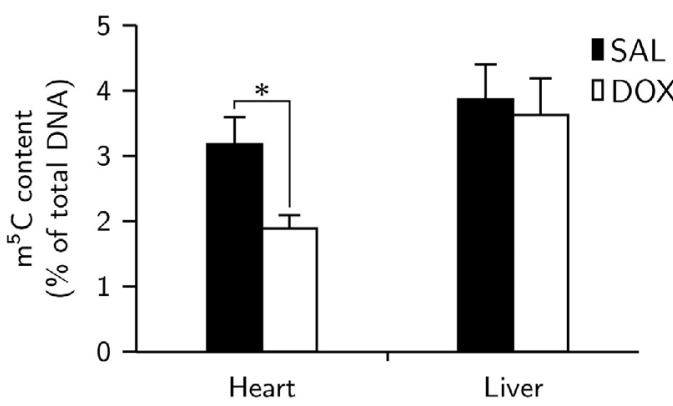

Fig. 4. DOX decreased the levels of transcripts involved in the metabolism of SAM and decreased global m5C content in cardiac tissue. (A) Heart mRNA levels of genes involved in DNA methylation and SAM metabolism were quantified by qPCR and normalized to $18 \mathrm{~S}$, TBP and $\beta$-actin ( $\mathrm{n}=4-5$ per group). (B) Global m5C content in DNA extracted from rat heart and liver tissue was examined by an ELISA assay ( $\mathrm{n}=5-6$ per group). *p $<0.05$ for the indicated comparisons. The post-hoc tests were the Student's $t$-test or the Welch's $t$-test, for datasets with homogenous or heterogeneous variances, respectively. Data are presented as mean \pm SEM. 
decreased mtDNA:nDNA copy numbers in liver tissue, suggesting that mtDNA alterations play a role in the cardiac-specific nature of DOX toxicity. It is important to note that, since mitochondrial turnover in the heart is about 14 days (Gottlieb and Stotland, 2015), some of the mitochondria present in the heart tissue at the final endpoint (14 days after the last injection) would have still been present when the animals were administered the final injection, and may therefore have been directly exposed to DOX. Since the liver has a faster mitochondrial turnover rate (2-4 days) (Kim et al., 2012; Miwa et al., 2008), hepatic mitochondria may recover faster from the DOX insult, and this may contribute to the selective DOX cardiotoxicity.

Mitochondrial DNA integrity in the heart, however, was not affected at our assessed time point. This result is not surprising, since the mtDNA repair machinery is likely to be able to fully cope with the rates of damage production that may be occurring at the time point assessed. For example, in studies measuring the effect of ischemia-reperfusion in heart, known to induce an instantaneous burst of ROS (Ambrosio et al., 1991), mtDNA damage is evident after $10 \mathrm{~min}$ of reperfusion, but returns to baseline levels after $60 \mathrm{~min}$ of reperfusion (Bliksoen et al., 2015). Assuming, however, that DOX induced mtDNA strand-break damage throughout the duration of our experimental protocol, one may speculate that a possible mechanism to resolve single- and doublestrand breaks would be the complete elimination of the damaged molecule, thus accounting, at least in part, for the observed decrease in mtDNA copy number. It is also important to note that the assay we employed is not specific to types of DNA damage that do not hamper DNA polymerase activity, such as oxidized bases. Therefore, although we have determined that subchronically DOX-treated rats do not display mtDNA strand-break lesions, mtDNA damage in the form of oxidized bases (such as 8-hydroxydeoxyguanosine [8-OHdG]) is likely to be in place, as it has already been implicated in subchronic DOX treatment (Serrano et al., 1999).

Curiously, the above results partly account for an interesting observation in a very relevant study by (Lebrecht et al., 2003). The authors, employing a model of persistent subchronic DOX toxicity in Wistar rats (sacrificed 31 weeks after the last injection), demonstrated a $50 \%$ decrease in mtDNA:nDNA copy number and a selective downregulation of mitochondrial OxPhos transcripts vs. nuclear OxPhos transcripts. Consistently, they further demonstrated a selective decrease in the enzymatic activity of cytochrome c oxidase (COX, a multisubunit complex encoded both by nDNA and mtDNA) vs. the activity of succinate dehydrogenase (SDH, encoded entirely by nDNA), again hinting at a mitochondrial-specific transcriptional imbalance. This suggests that at later stages, the heart can reestablish proper nDNA-encoded mitochondrial transcript levels, but not mtDNA-encoded mRNA. Future studies addressing this issue should be aimed at confirming not only this observation but also additional nDNA-encoded mitochondrial transcript levels, in order to provide a definitive answer to the unilateral nuclear reestablishment of mitochondrial transcription.

An additional major contributing factor to DOX-induced cardiotoxicity is the metabolic remodeling of cardiac tissue. We confirmed in our model previous results which demonstrate a decrease in transcripts involved in fatty acid oxidation in hearts from rats treated subchronically with DOX (Berthiaume and Wallace, 2007). Importantly, this was not accompanied by an upregulation of ACC2, which would be expected in a programmed, well concerted metabolic shift, since it encodes for an enzyme in an opposing pathway. This may be a contributing factor to the inhibition of fatty acid oxidation associated with DOX cardiotoxicity (Abdel-aleem et al., 1997; Bordoni et al., 1999).

The available literature suggests an interesting relationship between fatty acid oxidation and Ac-CoA production. There is substantial evidence implicating the carnitine shuttle system in the acquired metabolic inflexibility. For instance, it was previously shown that octanoate, a medium-chain fatty acid that does not require protein-mediated import into the mitochondrion, is equally oxidized by control and DOX treated rats (Carvalho et al., 2010). Conversely, long-chain fatty acids (which do require protein-mediated import) were shown to be inefficiently oxidized, suggesting that fatty acid transport is impaired with DOX treatment. However, no differences in gene expression or protein content of carnitine palmitoyltransferase I B (CPT1B) were found in this model (Berthiaume and Wallace, 2007; Carvalho et al., 2010). In a study investigating the effect of L-carnitine (the cofactor of CPT1B) in fatty acid oxidation, (Abdel-aleem et al., 1997) showed that the impairment in long-chain FFA oxidation is restored in DOX-treated rats co-administered L-carnitine. Nevertheless, the same animals also displayed an improvement in octanoate oxidation, suggesting that $\mathrm{L}^{-}$ carnitine administration may be exerting its effects on $\beta$-oxidation itself rather than on FFA transport. Indeed, considering that DOX greatly increases the Ac-CoA/CoA-SH ratio in isolated rat heart mitochondria (Ashour et al., 2012), it is plausible that L-carnitine acts as an Ac-CoA buffer, thus fully or partially restoring this equilibrium and thereby lifting the Ac-CoA-imposed inhibition of 3-ketoacyl-CoA thiolase - the final enzyme of the $\beta$-oxidation cycle. More importantly for our present work is the possibility of maintaining normal histone acetylation dynamics by preventing the increase in Ac-CoA/CoA-SH, thus potentially ameliorating the aberrant metabolic transcriptional profile. Our results support the role of L-carnitine in buffering excess mitochondrial AcCoA, since the observed downregulation of CACT may further contribute to this metabolic instability.

Since the assessment of Ac-CoA levels is not very straightforward, due to its low levels and stability, we assessed the cellular acetylome to verify if DOX treatment affects global lysine acetylation levels and/or patterns. No differences were found in whole cell levels of acetylated proteins (Fig. 2B-D). However, acetylation of a $\approx 63 \mathrm{kDa}$ protein was found to be absent in mitochondrial fractions from all DOX-treated rats. Such a selective pattern of acetylation clearly indicates that in our model, whole cell protein lysine acetylation status is not limited by eventual alterations to the metabolome but is instead responding to cellular signals that may culminate in, for example, changes in protein synthesis, degradation, translocation, repression of acetylases or activation of deacetylases (Choudhary et al., 2014). Future work is necessary to identify the protein corresponding to the absent band.

We report for the first time that DOX treatment disturbs mRNA levels of HATs and HDACs, two important classes of histone modulators. While there were no detectable differences in HAT enzymatic activity on either heart or liver tissue, the increased activity of HDACs measured in cardiac tissue appears to correlate with the only transcript that displayed increased levels (HDAC1). This result suggests that the expression of HDAC proteins may be following a similar trend to the one observed in the transcription patterns. The class I HDAC family consists of HDAC1, 2, 3 and 8. These are the most significant candidates for epigenetic modulation, since they co-localize predominantly in the nucleus and possess high enzymatic activity toward histone substrates (Haberland et al., 2009). Members of the class IIa HDAC family (HDAC4, 5, 7 and 9), conversely, possess a very low catalytic activity (Fischle et al., 2002; Jones et al., 2008) and their repressive role has been attributed mostly to their function as a scaffold protein in multiprotein transcriptional repressor complexes rather than any actual catalysis (Zhang et al., 2001). Thus, although we observe a generalized decrease in HDAC transcripts, our enzymatic activity assay agrees with a potential increased expression of class I HDAC proteins which would in turn be in concordance with the measured transcripts.

Because SAM levels are sensitive to environmental cues such as diet (Poirier et al., 2001), a strong mitochondrial toxicant such as DOX is likely to alter SAM levels as well. Although we were not able to set up an assay with enough sensitivity to assess SAM/SAH levels, we show that MAT2a (the enzyme that catalyzes the last step in SAM synthesis) was downregulated, suggesting that SAM synthesis may be impaired. A reduction in the SAM/SAH ratio would imply a reduction in DNA methylase activity, not only due to the limited substrate availability but also because SAH itself is a potent inhibitor of DNMTs (Selhub and Miller, 1992). Indeed, metabolic clearance of SAH is a key metabolic 
determinant to multiple methyltransferase reactions (Selhub and Miller, 1992). Furthermore, MAT2a has been shown to colocalize with the nucleus, specifically in chromatin-associated complexes. Absence of MAT2a in these complexes may further compromise the local production of SAM for methyltransferase reactions (Katoh et al., 2011), which may be more meaningful than global SAM synthesis for the purposes of DNA methylation. Decreased availability of MAT2a could be compensated for by MAT2b binding kinetics (Nordgren et al., 2011), which was not considered in our study. However, the global decrease in m5C levels in heart DNA from DOX-treated rats is in agreement with a decrease in SAM availability. Global DNA m5C content was not affected by DOX in liver tissue, also supporting a cardiac-specific nature of DOX toxicity. Paradoxically, reduction in global DNA m5C content was accompanied by a depression in the transcript levels of multiple genes. DNA methylation is an epigenetic mark mostly associated with transcriptional repression, therefore it is to be expected that a decrease in DNA methylation is followed by an increase in gene transcription. However, it is important to mention that DNA methylation is but one element in the myriad of complex factors governing chromatin modification. In addition, the method of methylation quantification employed in this study was limited to a global analysis, and provides no information regarding gene- or region-specific differences. This should be explored in followup studies.

Theoretically, decreased DNA methylation would be in agreement with a potential deregulation of folate metabolism and a concomitant decrease in the SAM/SAH ratio, as less methyl donors would be available to participate in DNA methylation. However, the available literature suggests that the relationship between SAM availability and DNA methylation does not follow this linear chain of thought. One in vitro study investigating the effect of folic acid supplementation in DNA methylation shows that deprivation of folic acid decreases the SAM/ SAH ratio but, also paradoxically, increases global DNA methylation (Farias et al., 2015). This effect appeared to be mediated mostly by changes in the expression of DNMTs 1 and 3a (which decreased by $50 \%$ and increased by $80 \%$, respectively) rather than variations in the metabolome. To fully elucidate the mechanisms by which DOX decreases DNA methylation, it will be essential to measure not only SAM and SAH levels but also the protein levels of the different DNA methylases.

Although in the present work, most of the affected transcripts were decreased, which could suggest a general inhibition of gene transcription that could be explained by the formation of stable DOX:DNA complexes, we believe that this is not a general unspecific effect, since the transcriptional levels of our genes-of-interest were normalized to 3 different reference genes that were not affected by the treatment with DOX.

Although we did not measure cardiac function at the tested or at later-time points, Moulin et al. (2015), using a similar animal model and protocol, showed that after 7 weeks of DOX treatment, male Wistar rats developed major signs of cardiomyopathy with cardiac atrophy, reduced left ventricular ejection fraction and 50\% mortality. Still, it must be stressed that we did not have any mortality in the DOX-treated group.

\section{Conclusions}

In summary, the present study provides novel insight and confirms previous data demonstrating the occurrence of metabolic, transcriptional and epigenetic changes after cessation of subchronic DOX treatment. These results are in agreement with the hypothesis that metabolite-mediated alteration of the cardiac epigenome is an underlying factor in the persistent nature of DOX-induced cardiotoxicity. Our study provides essential substantiating evidence that can be the framework for follow-up experiments with in vivo persistent toxicity models.

\section{Conflict of interest}

The authors declare that they have no conflict of interest relevant to this work. The funding agencies had no role in the decision to publish the manuscript.

\section{Acknowledgments}

This work was funded by grants from FEDER through the Operational Program for Competitiveness Factors-COMPETE 2020, FCT-Foundation for Science and Technology under research grants PTDC/DTP-FTO/1180/2012, POCI-01-0145-FEDER-016659, PTDC/ DTP-FTO/2433/2014, and strategic project POCI-01-0145-FEDER007440. Also supported by 3M Co. and QREN project 4832 with reference CENTRO-07-ST24-FEDER-002008 financed through FEDER. TC-O (SFRH/BPD/101169/2014) was supported by a FCT PostDoctoral fellowship.

\section{Appendix A. Supplementary data}

Supplementary data associated with this article can be found, in the online version, at http://dx.doi.org/10.1016/j.tox.2017.08.011.

\section{References}

Abdel-aleem, S., el-Merzabani, M.M., Sayed-Ahmed, M., Taylor, D.A., Lowe, J.E., 1997. Acute and chronic effects of adriamycin on fatty acid oxidation in isolated cardiac myocytes. J. Mol. Cell. Cardiol. 29 (2), 789-797. http://dx.doi.org/10.1006/jmcc. 1996.0323.

Ambrosio, G., Zweier, J.L., Flaherty, J.T., 1991. The relationship between oxygen radical generation and impairment of myocardial energy metabolism following post-ischemic reperfusion. J. Mol. Cell. Cardiol. 23 (12), 1359-1374.

Arcamone, F., Cassinelli, G., Fantini, G., et al., 2000. Adriamycin, 14-hydroxydaunomycin, a new antitumor antibiotic from S. peucetius var. caesius. Biotechnol. Bioeng. 67 (6), 704-713 Reprinted from Biotechnol. Bioeng. XI (6), 1101-1110 (1969) (2000).

Ascensao, A., Magalhaes, J., Soares, J.M., et al., 2005. Moderate endurance training prevents doxorubicin-induced in vivo mitochondriopathy and reduces the development of cardiac apoptosis. Am. J. Physiol. Heart Circ. Physiol. 289 (2), H722-H731. http://dx.doi.org/10.1152/ajpheart.01249.2004.

Ashour, A.E., Sayed-Ahmed, M.M., Abd-Allah, A.R., et al., 2012. Metformin rescues the myocardium from doxorubicin-induced energy starvation and mitochondrial damage in rats. Oxid. Med. Cell. Longev. 2012. http://dx.doi.org/10.1155/2012/434195.

Bar, J., Davidi, O., Goshen, Y., Hod, M., Yaniv, I., Hirsch, R., 2003. Pregnancy outcome in women treated with doxorubicin for childhood cancer. Am. J. Obstet. Gynecol. 189 (3), 853-857.

Berthiaume, J.M., Wallace, K.B., 2007. Persistent alterations to the gene expression profile of the heart subsequent to chronic Doxorubicin treatment. Cardiovasc. Toxicol. 7 (3), 178-191. http://dx.doi.org/10.1007/s12012-007-0026-0.

Bliksoen, M., Baysa, A., Eide, L., et al., 2015. Mitochondrial DNA damage and repair during ischemia-reperfusion injury of the heart. J. Mol. Cell. Cardiol. 78, 9-22. http://dx.doi.org/10.1016/j.yjmcc.2014.11.010.

Bordoni, A., Biagi, P., Hrelia, S., 1999. The impairment of essential fatty acid metabolism as a key factor in doxorubicin-induced damage in cultured rat cardiomyocytes. Biochim. Biophys. Acta 1440 (1), 100-106.

Campbell, C.T., Kolesar, J.E., Kaufman, B.A., 2012. Mitochondrial transcription factor A regulates mitochondrial transcription initiation, DNA packaging, and genome copy number. Biochim. Biophys. Acta 1819 (9-10), 921-929. http://dx.doi.org/10.1016/j. bbagrm.2012.03.002

Carvalho, C., Santos, R.X., Cardoso, S., et al., 2009. Doxorubicin: the good, the bad and the ugly effect. Curr. Med. Chem. 16 (25), 3267-3285.

Carvalho, R.A., Sousa, R.P., Cadete, V.J., et al., 2010. Metabolic remodeling associated with subchronic doxorubicin cardiomyopathy. Toxicology 270 (2-3), 92-98. http:// dx.doi.org/10.1016/j.tox.2010.01.019.

Carvalho, F.S., Burgeiro, A., Garcia, R., Moreno, A.J., Carvalho, R.A., Oliveira, P.J., 2014 Doxorubicin-induced cardiotoxicity: from bioenergetic failure and cell death to cardiomyopathy. Med. Res. Rev. 34 (1), 106-135. http://dx.doi.org/10.1002/med. 21280.

Che, R., Zhu, C., Ding, G., et al., 2015. Huaier cream protects against adriamycin-induced nephropathy by restoring mitochondrial function via PGC-1alpha upregulation. PPAR Res. 2015. http://dx.doi.org/10.1155/2015/720383.

Choudhary, C., Weinert, B.T., Nishida, Y., Verdin, E., Mann, M., 2014. The growing landscape of lysine acetylation links metabolism and cell signalling. Nat. Rev. Mol. Cell. Biol. 15 (8), 536-550. http://dx.doi.org/10.1038/nrm3841.

Crowell, A.M., Wall, M.J., Doucette, A.A., 2013. Maximizing recovery of water-soluble proteins through acetone precipitation. Anal. Chim. Acta 796, 48-54. http://dx.doi. org/10.1016/j.aca.2013.08.005.

Danz, E.D., Skramsted, J., Henry, N., Bennett, J.A., Keller, R.S., 2009. Resveratrol 
prevents doxorubicin cardiotoxicity through mitochondrial stabilization and the Sirt1 pathway. Free Red. Biol. Med. 46 (12), 1589-1597. http://dx.doi.org/10.1016/j freeradbiomed.2009.03.011.

Dimauro, I., Pearson, T., Caporossi, D., Jackson, M.J., 2012. A simple protocol for the subcellular fractionation of skeletal muscle cells and tissue. BMC Res. Notes 5, 513. http://dx.doi.org/10.1186/1756-0500-5-513.

Farias, N., Ho, N., Butler, S., et al., 2015. The effects of folic acid on global DNA methylation and colonosphere formation in colon cancer cell lines. J. Nutr. Biochem. 26 (8), 818-826. http://dx.doi.org/10.1016/j.jnutbio.2015.02.002.

Finck, B.N., 2007. The PPAR regulatory system in cardiac physiology and disease. Cardiovasc. Res. 73 (2), 269-277. http://dx.doi.org/10.1016/j.cardiores.2006.08. 023.

Fischle, W., Dequiedt, F., Hendzel, M.J., et al., 2002. Enzymatic activity associated with class II HDACs is dependent on a multiprotein complex containing HDAC3 and SMRT/N-CoR. Mol. Cell 9 (1), 45-57.

Gewirtz, D.A., 1999. A critical evaluation of the mechanisms of action proposed for the antitumor effects of the anthracycline antibiotics adriamycin and daunorubicin. Biochem. Pharmacol. 57 (7), 727-741.

Goormaghtigh, E., Chatelain, P., Caspers, J., Ruysschaert, J.M., 1980. Evidence of a complex between adriamycin derivatives and cardiolipin: possible role in cardiotoxicity. Biochem. Pharmacol. 29 (21), 3003-3010.

Gottlieb, R.A., Stotland, A., 2015. MitoTimer: a novel protein for monitoring mitochondrial turnover in the heart. J. Mol. Med. 93 (3), 271-278. http://dx.doi.org/10.1007 s00109-014-1230-6.

Guo, J., Guo, Q., Fang, H., et al., 2014. Cardioprotection against doxorubicin by metallothionein Is associated with preservation of mitochondrial biogenesis involving PGC-1alpha pathway. Eur. J. Pharmacol. 737, 117-124. http://dx.doi.org/10.1016/j ejphar.2014.05.017.

Haberland, M., Montgomery, R.L., Olson, E.N., 2009. The many roles of histone deacetylases in development and physiology: implications for disease and therapy. Nat. Rev. Genet. 10 (1), 32-42. http://dx.doi.org/10.1038/nrg2485.

Johnson, D., Perrault, H., Fournier, A., Leclerc, J.M., Bigras, J.L., Davignon, A., 1997. Cardiovascular responses to dynamic submaximal exercise in children previously treated with anthracycline. Am. Heart J. 133 (2), 169-173.

Jones, P., Altamura, S., De Francesco, R., et al., 2008. Probing the elusive catalytic activity of vertebrate class IIa histone deacetylases. Bioorg. Med. Chem. Lett. 18 (6), 1814-1819. http://dx.doi.org/10.1016/j.bmcl.2008.02.025.

Katoh, Y., Ikura, T., Hoshikawa, Y., et al., 2011. Methionine adenosyltransferase II serves as a transcriptional corepressor of Maf oncoprotein. Mol. Cell 41 (5), 554-566. http://dx.doi.org/10.1016/j.molcel.2011.02.018.

Kim, T.Y., Wang, D., Kim, A.K., et al., 2012. Metabolic labeling reveals proteome dynamics of mouse mitochondria. Mol. Cell. Proteomics 11 (12), 1586-1594. http://dx. doi.org/10.1074/mcp.M112.021162.

Kouzarides, T., 2007. Chromatin modifications and their function. Cell 128 (4), 693-705. http://dx.doi.org/10.1016/j.cell.2007.02.005

Kovalenko, O.A., Santos, J.H., 2009. Analysis of oxidative damage by gene-specific quantitative PCR. Current protocols in human genetics/editorial board, Jonathan L Haines [et al] Chapter 19: Unit 191 10.1002/0471142905.hg1901s62.

Lebrecht, D., Setzer, B., Ketelsen, U.P., Haberstroh, J., Walker, U.A., 2003. Time-dependent and tissue-specific accumulation of mtDNA and respiratory chain defects in chronic doxorubicin cardiomyopathy. Circulation 108 (19), 2423-2429. http://dx. doi.org/10.1161/01.CIR.0000093196.59829.DF.

Lefrak, E.A., Pitha, J., Rosenheim, S., Gottlieb, J.A., 1973. A clinicopathologic analysis of adriamycin cardiotoxicity. Cancer 32 (2), 302-314.

Lu, S.C., Mato, J.M., 2012. S-adenosylmethionine in liver health, injury, and cancer. Physiol. Rev. 92 (4), 1515-1542. http://dx.doi.org/10.1152/physrev.00047.2011.

Machado, N.G., Baldeiras, I., Pereira, G.C., Pereira, S.P., Oliveira, P.J., 2010. Sub-chronic administration of doxorubicin to Wistar rats results in oxidative stress and unaltered apoptotic signaling in the lung. Chem. Biol. 188 (3), 478-486. http://dx.doi.org/10. 1016/j.cbi.2010.09.027.

Marques-Aleixo, I., Santos-Alves, E., Mariani, D., et al., 2015. Physical exercise prior and during treatment reduces sub-chronic doxorubicin-induced mitochondrial toxicity and oxidative stress. Mitochondrion 20, 22-33. http://dx.doi.org/10.1016/j.mito. 2014.10.008.

Miwa, S., Lawless, C., von Zglinicki, T., 2008. Mitochondrial turnover in liver is fast in vivo and is accelerated by dietary restriction: application of a simple dynamic model. Aging Cell 7 (6), 920-923. http://dx.doi.org/10.1111/j.1474-9726.2008.00426.x.

Moulin, M., Piquereau, J., Mateo, P., et al., 2015. Sexual dimorphism of doxorubicinmediated cardiotoxicity: potential role of energy metabolism remodeling. Circ. Heart Fail. 8 (1), 98-108. http://dx.doi.org/10.1161/CIRCHEARTFAILURE.114.001180.

Munday, M.R., Hemingway, C.J., 1999. The regulation of acetyl-CoA carboxylase-a potential target for the action of hypolipidemic agents. Adv. Enzyme Reg. 39, 205-234.

Nicolay, K., Fok, J.J., Voorhout, W., Post, J.A., de Kruijff, B., 1986. Cytofluorescence detection of adriamycin-mitochondria interactions in isolated, perfused rat heart. Biochim. Biophys. Acta 887 (1), 35-41.

Nordgren, K.K., Peng, Y., Pelleymounter, L.L., et al., 2011. Methionine adenosyltransferase $2 \mathrm{~A} / 2 \mathrm{~B}$ and methylation: gene sequence variation and functional genomics. Drug Metab. Dispos. 39 (11), 2135-2147. http://dx.doi.org/10.1124/dmd.111. 040857.

Octavia, Y., Tocchetti, C.G., Gabrielson, K.L., Janssens, S., Crijns, H.J., Moens, A.L., 2012. Doxorubicin-induced cardiomyopathy: from molecular mechanisms to therapeutic strategies. J. Mol. Cell. Cardiol. 52 (6), 1213-1225. http://dx.doi.org/10.1016/j. yjmcc.2012.03.006.

Pereira, G.C., Pereira, S.P., Pereira, C.V., et al., 2012. Mitochondrionopathy phenotype in doxorubicin-treated Wistar rats depends on treatment protocol and is cardiac-specific. PLoS One 7 (6), e38867. http://dx.doi.org/10.1371/journal.pone.0038867.

Pereira, G.C., Pereira, S.P., Tavares, L.C., et al., 2016. Cardiac cytochrome c and cardiolipin depletion during anthracycline-induced chronic depression of mitochondrial function. Mitochondrion 30, 95-104. http://dx.doi.org/10.1016/j.mito.2016.07.005.

Peters, J.H., Gordon, G.R., Kashiwase, D., Acton, E.M., 1981. Tissue distribution of doxorubicin and doxorubicinol in rats receiving multiple doses of doxorubicin. Cancer Chemother. Pharmacol. 7 (1), 65-69.

Pfaffl, M.W., 2001. A new mathematical model for relative quantification in real-time RTPCR. Nucleic Acids Res. 29 (9), e45.

Poirier, L.A., Wise, C.K., Delongchamp, R.R., Sinha, R., 2001. Blood determinations of S adenosylmethionine, S-adenosylhomocysteine, and homocysteine: correlations with diet. Cancer Epidemiol. Biomarkers Prev. 10 (6), 649-655.

Richard, C., Ghibu, S., Delemasure-Chalumeau, S., et al., 2011. Oxidative stress and myocardial gene alterations associated with Doxorubicin-induced cardiotoxicity in rats persist for 2 months after treatment cessation. J. Pharmacol. Exp. Ther. 339 (3), 807-814. http://dx.doi.org/10.1124/jpet.111.185892.

Romero-Calvo, I., Ocon, B., Martinez-Moya, P., et al., 2010. Reversible Ponceau staining as a loading control alternative to actin in Western blots. Anal. Biochem. 401 (2), 318-320. http://dx.doi.org/10.1016/j.ab.2010.02.036.

Russo, S., Filippelli, W., Ferraraccio, F., Berrino, L., Guarino, V., Rossi, F., 1994. Effects of S-adenosylmethionine (SAMe) on doxorubicin-induced cardiotoxicity in the rat. J. Med. 25 (1-2), 65-89.

Scarpulla, R.C., 2006. Nuclear control of respiratory gene expression in mammalian cells. J. Cell. Biochem. 97 (4), 673-683. http://dx.doi.org/10.1002/jcb.20743.

Scarpulla, R.C., 2011. Metabolic control of mitochondrial biogenesis through the PGC-1 family regulatory network. Biochim. Biophys. Acta 1813 (7), 1269-1278. http://dx. doi.org/10.1016/j.bbamcr.2010.09.019.

Schlame, M., Ren, M., 2006. Barth syndrome, a human disorder of cardiolipin metabolism. FEBS Lett. 580 (23), 5450-5455. http://dx.doi.org/10.1016/j.febslet.2006.07. 022 .

Selhub, J., Miller, J.W., 1992. The pathogenesis of homocysteinemia: interruption of the coordinate regulation by S-adenosylmethionine of the remethylation and transsulfuration of homocysteine. Am. J. Clin. Nutr. 55 (1), 131-138.

Serrano, J., Palmeira, C.M., Kuehl, D.W., Wallace, K.B., 1999. Cardioselective and cumulative oxidation of mitochondrial DNA following subchronic doxorubicin administration. Biochim. Biophys. Acta 1411 (1), 201-205.

Simunek, T., Sterba, M., Popelova, O., Adamcova, M., Hrdina, R., Gersl, V., 2009. Anthracycline-induced cardiotoxicity: overview of studies examining the roles of oxidative stress and free cellular iron. Pharmacol. Rep. 61 (1), 154-171.

Smiraglia, D.J., Kulawiec, M., Bistulfi, G.L., Gupta, S.G., Singh, K.K., 2008. A novel role for mitochondria in regulating epigenetic modification in the nucleus. Cancer Biol. Ther. 7 (8), 1182-1190.

Solem, L.E., Heller, L.J., Wallace, K.B., 1996. Dose-dependent increase in sensitivity to calcium-induced mitochondrial dysfunction and cardiomyocyte cell injury by doxorubicin. J. Mol. Cell. Cardiol. 28 (5), 1023-1032. http://dx.doi.org/10.1006/jmcc. 1996.0095.

Steinherz, L.J., Steinherz, P.G., Tan, C.T., Heller, G., Murphy, M.L., 1991. Cardiac toxicity 4 to 20 years after completing anthracycline therapy. JAMA 266 (12), 1672-1677.

Sterba, M., Popelova, O., Vavrova, A., et al., 2013. Oxidative stress, redox signaling, and metal chelation in anthracycline cardiotoxicity and pharmacological cardioprotection. Antioxid. Redox Signal. 18 (8), 899-929. http://dx.doi.org/10.1089/ars.2012. 4795.

Suliman, H.B., Carraway, M.S., Ali, A.S., Reynolds, C.M., Welty-Wolf, K.E., Piantadosi, C.A., 2007. The CO/HO system reverses inhibition of mitochondrial biogenesis and prevents murine doxorubicin cardiomyopathy. J. Clin. Invest. 117 (12), 3730-3741. http://dx.doi.org/10.1172/JCI32967.

Tokarska-Schlattner, M., Wallimann, T., Schlattner, U., 2006. Alterations in myocardial energy metabolism induced by the anti-cancer drug doxorubicin. C. R. Biol. 329 (9), 657-668. http://dx.doi.org/10.1016/j.crvi.2005.08.007.

Vandesompele, J., De Preter, K., Pattyn, F., et al., 2002. Accurate normalization of real time quantitative RT-PCR data by geometric averaging of multiple internal control genes. Genome Biol. 3 (7) RESEARCH0034.

Ventura-Clapier, R., Garnier, A., Veksler, V., 2008. Transcriptional control of mitochondrial biogenesis: the central role of PGC-1alpha. Cardiovasc. Res. 79 (2), 208-217. http://dx.doi.org/10.1093/cvr/cvn098.

Wallace, D.C., Fan, W., 2010. Energetics, epigenetics, mitochondrial genetics. Mitochondrion 10 (1), 12-31. http://dx.doi.org/10.1016/j.mito.2009.09.006.

Wallace, K.B., 2003. Doxorubicin-induced cardiac mitochondrionopathy. Pharmacol. Toxicol. 93 (3), 105-115.

Yang, F., Teves, S.S., Kemp, C.J., Henikoff, S., 2014. Doxorubicin, DNA torsion, and chromatin dynamics. Biochim. Biophys. Acta 1845 (1), 84-89. http://dx.doi.org/10. 1016/j.bbcan.2013.12.002.

Yokochi, T., Robertson, K.D., 2004. Doxorubicin inhibits DNMT1, resulting in conditiona apoptosis. Mol. Pharmacol. 66 (6), 1415-1420. http://dx.doi.org/10.1124/mol.104. 002634.

Zhang, C.L., McKinsey, T.A., Lu, J.R., Olson, E.N., 2001. Association of COOH-terminalbinding protein (CtBP) and MEF2-interacting transcription repressor (MITR) contributes to transcriptional repression of the MEF2 transcription factor. J. Biol. Chem. 276 (1), 35-39. http://dx.doi.org/10.1074/jbc.M007364200.

Zhou, S., Starkov, A., Froberg, M.K., Leino, R.L., Wallace, K.B., 2001. Cumulative and irreversible cardiac mitochondrial dysfunction induced by doxorubicin. Cancer Res. 61 (2), 771-777. 